\title{
Use of electronic personal health record systems to encourage HIV screening: an exploratory study of patient and provider perspectives
}

D Keith Mclnnes ${ }^{1,2^{*}}$, Jeffrey L Solomon ${ }^{1}$, Barbara G Bokhour ${ }^{1,2}$, Steven M Asch ${ }^{3,4}$, David Ross ${ }^{5}$, Kim M Nazi ${ }^{6}$ and Allen L Gifford ${ }^{1,2,7}$

\begin{abstract}
Background: When detected, HIV can be effectively treated with antiretroviral therapy. Nevertheless in the U.S. approximately $25 \%$ of those who are HIV-infected do not know it. Much remains unknown about how to increase HIV testing rates. New Internet outreach methods have the potential to increase disease awareness and screening among patients, especially as electronic personal health records (PHRs) become more widely available. In the US Department of Veterans' Affairs medical care system, 900,000 veterans have indicated an interest in receiving electronic health-related communications through the PHR. Therefore we sought to evaluate the optimal circumstances and conditions for outreach about HIV screening. In an exploratory, qualitative research study we examined patient and provider perceptions of Internet-based outreach to increase HIV screening among veterans who use the Veterans Health Administration (VHA) health care system.
\end{abstract}

Findings: We conducted two rounds of focus groups with veterans and healthcare providers at VHA medical centers. The study's first phase elicited general perceptions of an electronic outreach program to increase screening for HIV, diabetes, and high cholesterol. Using phase 1 results, outreach message texts were drafted and then presented to participants in the second phase. Analysis followed modified grounded theory.

Patients and providers indicated that electronic outreach through a PHR would provide useful information and would motivate patients to be screened for HIV. Patients believed that electronic information would be more convenient and understandable than information provided verbally. Patients saw little difference between messages about HIV versus about diabetes and cholesterol. Providers, however, felt patients would disapprove of HIV-related messages due to stigma. Providers expected increased workload from the electronic outreach, and thus suggested adding primary care resources and devising methods to smooth the flow of patients getting screened. When provided a choice between unsecured emails versus PHRs as the delivery mechanism for disease screening messages, both patients and providers preferred PHRs.

Conclusions: There is considerable potential to use PHR systems for electronic outreach and social marketing to communicate to patients about, and increase rates of, disease screening, including for HIV. Planning for direct-topatient communications through PHRs should include providers and address provider reservations, especially about workload increases.

\footnotetext{
* Correspondence: keith.mcinnes@va.gov

${ }^{1}$ Center for Health Quality, Outcomes \& Economic Research, ENRM VA

Medical Center, Bedford, MA, USA

Full list of author information is available at the end of the article
} 


\section{Background}

Arguments for expanding HIV screening are compelling. When detected, HIV can be effectively treated with antiretroviral therapy (ART), which improves patient survival, helps prevent HIV transmission, and is cost effective [1-3]. Nevertheless in the U.S. approximately $25 \%$ of those who are HIV-infected do not know it $[4,5]$. Much remains unknown about how to increase HIV testing rates in the US.

Direct outreach to patients via the Internet is a potentially efficient means of educating patients about the importance of HIV screening. Patient electronic personal health record (PHR) systems may be a useful vehicle for such outreach [6-8]. Little is known, however, about how patients and healthcare providers would perceive use of the PHR to disseminate disease screening messages, or whether such messages would increase HIV testing, e.g. by increasing patient knowledge [9], self-efficacy [10], and activation [11]. Additionally this type of outreach could raise patient concerns about privacy of information on the Internet, especially for stigmatized conditions like HIV. Providers may have concerns that workload will increase, or that direct-to-patient outreach circumvents provider authority. While electronic outreach for health purposes is not new, it has largely been evaluated in the context of randomized trials of specific interventions [12-14], or newsletters for which consumers pro-actively register [15]. Little is known about how providers and patients within a large health care organization would perceive large-scale, unsolicited, outreach via an electronic personal health record system to encourage HIV screening.

As the largest provider of HIV care in the U.S., the Department of Veterans Affairs (VA) is well suited for evaluating different methods for increasing HIV testing. The VA already devotes considerable effort to increasing HIV screening rates [16], including clinical reminders in the electronic medical record, provider performance profiling, and reducing paperwork barriers to testing [17-19]. Still, testing rates are sub-optimal, with an estimated $20 \%$ to $50 \%$ of VA patients with documented risk factors for HIV infection having been tested [20-22]. The VA's electronic PHR, My HealtheVet, contains email addresses of nearly 1,000,000 veterans, most of whom (87\%) report using VA health care [23]. Thus the VA is an appropriate system for implementing and evaluating large scale electronic outreach for HIV screening. The VA PHR was (and is) evolving rapidly, with new versions released approximately every 6 months (current version is 11.2). In addition, at the time of this study the VA was preparing to adopt new Centers for Disease Control and Prevention (CDC) recommendations for routine, instead of risk-based, HIV testing. Among other things this involved the elimination of the requirement to obtain written patient consent prior to testing. In the context of this rapidly changing landscape we selected methods which would quickly provide VA policy makers with preliminary patient and provider perceptions of the use of the PHR to encourage more HIV screening.

We explored patient and provider attitudes toward an electronic outreach program for HIV screening, based on a PHR platform. We conducted focus groups with patients and providers about HIV testing. We also discussed diabetes and cholesterol screening with participants to assess whether attitudes toward outreach to increase screening depended on the health condition. We explored the acceptability of messages embedded directly in personal emails versus messages posted on the PHR website. Our focus group guides were informed by the Information-Motivation-Behavioral Skills (IMB) model which has guided health promotion and chronic disease management, including HIV [24,25]. We used the model to guide broad categories of questions to include in the focus groups. Qualitative methods were used because, with such new areas of research, it is important to identify salient patient and provider perceptions and themes prior to embarking on larger scale quantitative research [26-28].

\section{Methods}

\section{Overview}

Four focus groups were conducted between September 2008 and March 2009, in two phases (Figure 1). The first phase explored HIV screening (and other disease screening) in general terms and sought participant suggestions about the content and framing of the electronic outreach messages. Results from this phase guided the investigators in drafting the content of messages. In the second phase, we presented participants the draft text of HIV, diabetes, and cholesterol screening messages in order to explore patient and provider perceptions of realistic content. It was important to compare perceptions of other chronic health conditions to HIV in order to assess whether HIV-related stigma would adversely affect acceptance of HIV screening messages. The message text was based on VA and Centers for Disease Control and Prevention (CDC) screening guidelines, as well as findings from the phase 1 focus groups. The Institutional Review Board of the Edith Nourse Rogers Memorial VA Medical Center, Bedford, MA approved the study including all recruitment methods. Study subjects completed written informed consent prior to participating.

\section{Participants and Setting}

A total of 12 patients (6 in each focus group) and 15 providers (6 in one focus group, 9 in the other) 


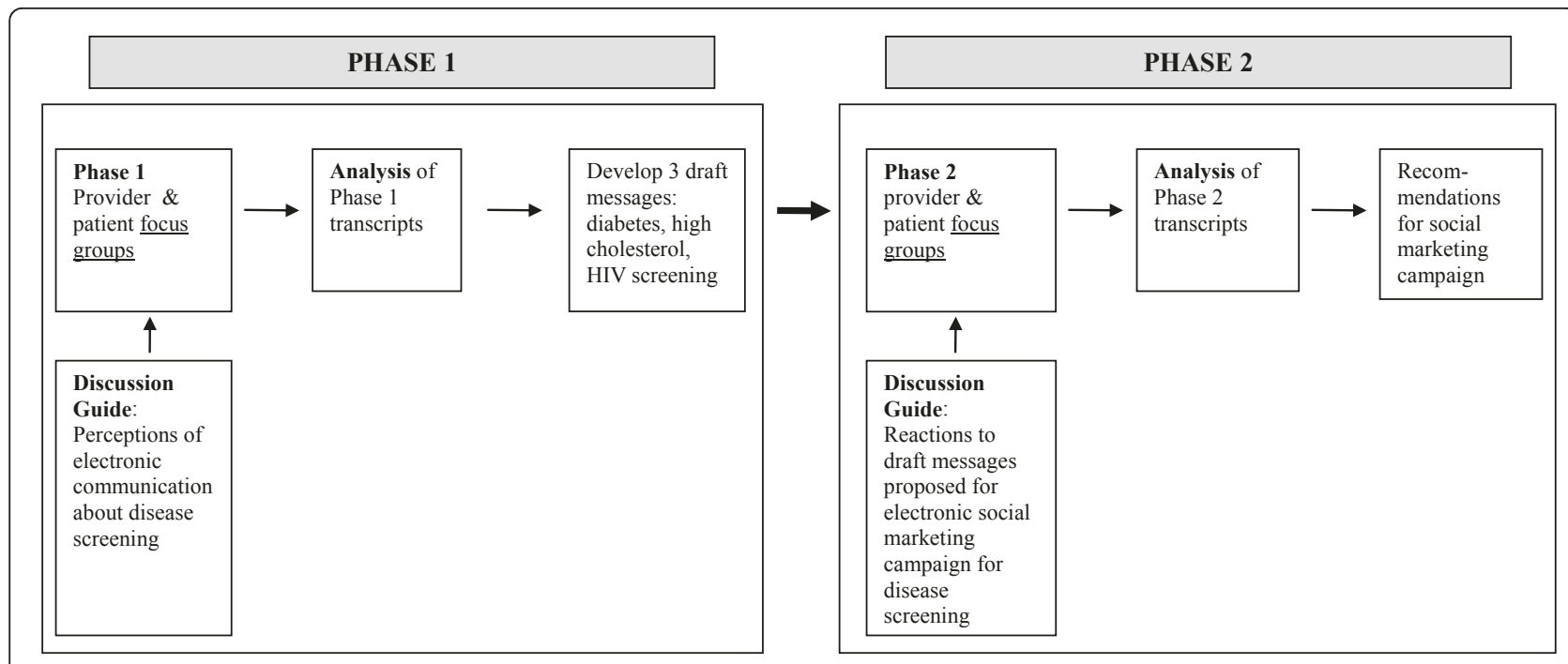

Figure 1 Study components and flow

participated. Patients were recruited from a Boston area VA medical center. We posted recruitment fliers on walls and a "crawler" message on the televisions in the medical center waiting areas. We also approached veterans at new-patient orientation sessions and in the veterans computer center (KM and LM). Patients received $\$ 20$ for their participation.

Primary care providers were recruited from another urban New England VA medical center. The invitation to providers was extended by a research team member (KM) who described the study at a primary care staff meeting. Providers were not compensated for participating.

\section{Procedures}

There were two facilitators (KM and JS) for each focus group. Following the IMB model, we developed focus group guides to explore whether the concept of electronic disease screening messages, and message content, were perceived as providing valuable information. Secondly questions assessed how likely the information was to motivate patients to seriously consider being tested, and how likely they would be to take action, i.e. ask their provider for a test (behavioral skills). More specifically, the phase 1 patient focus group guide covered experience with disease screening; sources of information about disease screening; experience with Internet and My HealtheVet; and, attitudes toward the proposed VA electronic outreach program to increase disease screening rates. The phase 2 patient guide elicited reactions to draft texts of messages for HIV, cholesterol, and diabetes screening (Figure 2) that might be part of the VA disease screening outreach program. Patient focus groups lasted two hours.
The phase 1 provider focus group guide elicited discussion of how providers decide to screen individual patients for diseases; provider views of patient requests for disease screening; provider perceptions of the proposed electronic outreach program; and their assessments of how patients would react to such a program. The phase 2 guide asked providers for their reactions to the same draft messages (for HIV, cholesterol, diabetes) that were shown to patients (Figure 2). They were asked how they anticipated their patients would respond, what questions their patients might ask, and what they thought patient reaction would be. Provider focus groups lasted one hour.

While the research was conducted in two phases, with separate focus group guides for each phase, the results are presented by themes, rather than phase. This is because there was considerable overlap between the focus group guides from the first and second phases. Hence the themes we uncovered emerged from all four focus groups. We have indicated after each quote which phase it came from, e.g. "Patient FG1" refers to first phase patient focus group. Because the focus group guides are lengthy (they make extensive use of probes and prompts that the focus group facilitator can use at his or her discretion) they are not included here, however they are provided for interested readers in Additional File 1: Focus group guides used for patients and providers. All focus groups were audio-taped and transcribed.

\section{Analysis}

We used an iterative process to guide the analysis and interpret data, based on grounded theory methods [29]. Immediately following each focus group the facilitators discussed their impressions of significant points that 


\section{Dear Veteran:}

Did you know that the VA encourages veterans to get a variety of routine health tests, such as checking your cholesterol? Read below to see why.

\section{Why check my cholesterol?}

- Over 100 million American adults have cholesterol levels which are higher than recommended.

- Having high blood cholesterol can put you at risk for heart disease, the leading cause of death in the US.

- Adults aged 20 years or older should have their cholesterol checked every 5 years.

- If you think you may not have had a cholesterol test in the past 5 years, ask your provider at your next visit.

The good news!: Cholesterol can be lowered through diet, physical activity, weight control and medication.

\section{Dear Veteran:}

Did you know that the VA encourages veterans to get a variety of routine health tests, such as testing for diabetes? Read below to see why.

\section{Why check for diabetes?}

- About 24 million Americans have diabetes, but one quarter of these people don't know they have it, because they haven't been tested recently.

- Diabetes can cause serious health problems like heart disease, strokes, blindness, and kidney disease.

- Adults aged 45 years or older should have their blood sugar checked (the test for diabetes) at least every 3 years.

- If you have not had your blood sugar checked in the past 3 years, or if you are unsure, ask your provider at your next visit.

The good news!: If you don't have diabetes, your provider can help you keep it that way. If you do have diabetes, your provider can tell you many ways to control it.

\section{Dear Veteran: \\ Did you know that the VA encourages veterans to get a variety of routine health tests, such as testing for HIV disease? Read below to see why.}

\section{Why check for HIV disease?}

- Over 1 million Americans have HIV. Unfortunately a quarter of the people who have HIV don't know they have it because they have never been tested.

- Having HIV but not knowing you have it means that you could spread the virus to other people. Also, untreated HIV causes AIDS, which is a very serious disease.

- $\quad$ The Centers for Disease Control (CDC) recommends that all adults get tested for HIV.

- If you think you may not have been tested for HIV, or are unsure, ask your provider at your next visit.

The good news!: Most people tested for HIV don't have it. But if you do have HIV you won't lose any VA benefits, and the VA has excellent health care for HIV.

Figure 2 Text of electronic messages shown to patients and providers in focus groups

emerged from the focus group. In addition, within a week the facilitators briefed the whole research team, summarizing the focus group content, and eliciting comments about emerging themes. Audio-recordings were transcribed verbatim by a professional transcription firm. Focus group facilitators (KM and JS) verified the transcripts and analyzed them by open coding, i.e. identifying key concepts emerging from the language used by participants, and assigning codes (descriptive phrases) to segments of text. NVivo 
qualitative analysis software (QSR, Melbourne, Australia) was used to facilitate data coding and sorting. Coded text segments were reviewed by three investigators (KM, $\mathrm{JS}$, and $\mathrm{BB}$ ) to categorize codes into distinct themes. Where similar themes were identified in patient and provider transcripts, we examined similarities and differences in patient and provider perspectives. In a final phase, after developing preliminary interpretations, we searched through the data for alternative interpretations and rival conclusions.

\section{Results}

\section{Participant Characteristics}

Patients ranged in age from 48 to 71 years of age. Most were white and male. Two-thirds were Internet users (used email and/or the Internet). All had some college education. The 5 physicians and 7 primary-care nurse practitioners participating ranged in age from 46-60 years (see Table 1).

\section{Overview of findings}

Patients and providers perceived important informational and educational benefits of the proposed electronic outreach. Several providers expressed substantial privacy concerns related to the social stigma associated with HIV. Patients, for the most part, did not perceive HIV messages to be inherently more sensitive than messages about diabetes and cholesterol. Providers anticipated increased workload and made recommendations for message content in order to minimize disruption to primary care practice.

\section{Perceived benefits for patients of screening messages in general}

The more information the better

Patients and providers perceived that electronic disease screening outreach would improve patient access to useful health information, with important educational value. For providers there was a perception that it would reinforce messages they give to patients. Patients seemed interested in more information, and saw this outreach as a potentially good way to achieve this goal. Here, a patient expresses his view that too many people take their bodies and their health for granted, and that the messages proposed could help combat this complacency.

"I think all this information would be great. Because I think how else are we going to know what to do with the only true asset we own [which] is our body. And some people spend more time getting the oil changed in their car than they do worrying about what's going on in [their bodies]." (Patient FG2)

Providers realized that their repeated recommendations to patients to be screened lose effectiveness. Using a new medium, i.e. the Internet, could be a useful adjunct to what providers are trying to communicate to their patients.

"I think for established patients, this is reinforcing education. The last sentence [of the draft text shown to providers], 'Cholesterol can be lowered,' they're hearing that all the time from us. And now they're reading it, so [it's] another teaching tool." (Provider FG2)

\section{Information using lay language and available when patients are ready for it}

Patients could imagine scenarios in which disease screening information provided electronically would be better than verbal information from their doctor. The patient below knows there are times when other factors, in this instance substance use, interfere with his ability

Table 1 Characteristics of focus group participants

\begin{tabular}{|c|c|c|}
\hline & Patient Focus Groups & Provider Focus Groups \\
\hline \multirow[t]{2}{*}{ Number } & 6 in group 1 & 6 in group 1 \\
\hline & 6 in group 2 & 9 in group $2^{*}$ \\
\hline Gender & 2 female; 10 male & 8 female; 4 male \\
\hline \multirow[t]{4}{*}{ Race/Ethnicity } & 9 white & [Not collected] \\
\hline & 1 African American & \\
\hline & 1 Hispanic & \\
\hline & 1 Pacific Islander/Hawaiian & \\
\hline \multirow[t]{3}{*}{ Education/Qualifications } & 6 some college or college degree & 7 nurse practitioners \\
\hline & 3 some graduate or graduate degree & 5 medical doctors \\
\hline & 3 not provided & \\
\hline Age & 48 to 71 years & 46 to 60 years \\
\hline
\end{tabular}

* There were 12 unique providers because 3 providers participated in both focus groups. 
to absorb important messages from his doctor.

"Let's say I went in from detox. [My doctor] might be saying all this stuff to me but I might be in a situation where I'm like, 'I ain't listening to all this stuff at this point now.' When my head starts to clear out [I might think] 'Okay. What did this doctor say?" (Patient FG2)

An electronic message gives the patient another opportunity to receive the information, and the choice of when and how many times to read it. These messages can be carefully worded to accommodate low literacy levels, as expressed by this patient,

"If you put [the web information] in layman's terms pretty much explaining LDL or HDL... and how you get it, [that's better than having] \$20 dollar words in there." (Patient FG2)

\section{Messages can motivate patients}

Patients felt that electronic outreach would motivate them to be proactive about their health. Most felt the electronic messages would remind them to be screened, or at least contemplate getting screened. Here a patient finds the idea of an email about HIV screening to be non-threatening, and potentially motivating.

“They're not telling you [you have to be tested for HIV]. They're putting it in your mind saying... "Have you ever thought about getting HIV testing?" It's non-offensive. You're not prying. But it gets you thinking. Something like that might work." (Patient FG1)

Below, two patients, discussing diabetes screening, conclude that outreach messages would be valuable, despite their different perceived risk for the condition. The first realizes that a common "if it's not broken, don't fix it" attitude, may prevent people from thinking about getting preventive testing.

"As far as [an email] prompting you to go and get [a test] done, yeah there's probably people that aren't even aware that they should have them. Up until five years ago, I never thought about getting my blood sugar checked. What do I care? It's not bothering me any." (Patient FG2)

The second patient has a family history of diabetes that he/she might inadvertently ignore. Periodic reminders can be the extra motivation to take action and get tested.
"My father has diabetes. My mother is borderline diabetes [sic]. I've been checked periodically through the years and I don't seem to be having it...It might slip my mind where I'm not thinking I'm going to get it...and then all of a sudden I see [the electronic message about diabetes screening] and I say, 'Maybe I ought to go and have it checked.' So it's kind of like a kick in the pants." (Patient FG2)

\section{HIV content: patient acceptance, provider wariness}

Our focus group questions sought to contrast electronic outreach for non-sensitive conditions (i.e. diabetes and cholesterol) with HIV, a stigmatized condition. Few patients, however, made this distinction. Patients thought electronic messages about HIV were acceptable and useful, especially if they were clearly written as public health announcements for wide distribution. One patient likened HIV information delivered electronically through the PHR to posters about HIV testing found in many VA medical center waiting rooms; while another felt that because the material was for a generic patient audience it would not raise objections:

"I wouldn't mind [getting a message about HIV testing]; it's pasted all over the walls of the VA. I mean, I think the information is good." (Patient FG2)

"None of this is laden with any personal information on yourself or anything like that...I can't see any of this being upsetting to anybody." (Patient FG2)

A third patient, however, speaking about messages sent to personal email addresses, was worried about possible security breaches and the stigma of being associated with HIV. He suspected that once information entered his computer it would be difficult to erase, thus allowing later users to find such messages.

"I don't want 'You get tested for HIV' [in an email]... I've given away computers I've had to people who never had one... They can get into your mainframe, as you folks may know. They can find stuff that you left in there. I'm not taking that chance.... I'm very careful about what goes in my computer. I have a disk that I put everything on. I don't let it go on my mainframe. But some stuff goes in there. You think I want to take a chance and let HIV go in there? And they accidentally find it? Hell, no!" (Patient FG1)

This type of concern supports placing the disease screening messages on the PHR website, rather than delivering it directly into patient email inboxes. This sentiment is summarized by a patient in the first focus 
group (referring to the PHR by its VA name, "My HealtheVet"):

"I would like to see [a message in my personal email stating] "You have messages at My HealtheVet." That's all I want to see. Just tell me to go My HealtheVet website, log in and I get messages there. I'd rather see a message there than coming into [my personal email]." (Patient FG1)

Providers aired substantially more concerns about HIV messages than patients. Some providers felt that patients would be irresponsible with emails containing HIVrelated content. The provider below, for example, described how patients easily find doctor email addresses, and could send their doctors inappropriate email. The provider expresses two issues: the risk that the patient becomes associated, in other people's minds, with a stigmatized condition, and the risk that providers get criticized from their employer for participating in inappropriate email use.

"I see a lot of problems with this, because there are going to be some [veterans] who aren't thinking about confidentiality. And they're going to be emailing their provider, which is 'my name-dot-VA-dotgov'; And they're going to be saying 'Oh, I got this thing on HIV. I think I should be tested.' And it's going to be out there in the Internet world, floating around. And the VA is going to get dinged - or me - for 'Oh my God, why did this person email you about this?"' (Provider FG2)

This provider expresses the view, correct in some instances, that regular email messages are vulnerable because they "float around" in the Internet easily opened and read by other Internet users.

Another aspect of provider resistance toward HIVrelated emails was that they could create suspicions among patients that the VA is withholding information from patients:

"And I think if you sent them an email, there are some people who might be walking in the next day, 'I got this email that told me to come in and be tested!...Why are you worried?...Why'd you send it to me? Did you send it to anybody else?'" (Provider FG1)

This view may reflect provider sensitivity to claims by veterans and active duty military that the US government releases too slowly important health-related information, especially for risks related to military service [30].
Finally, another provider's hesitation was that the HIV message was inappropriate because it was promoting a substantial deviation from the way providers recommended HIV testing. One provider remarked, "...this third [message] on HIV is like a bombshell," because it recommended routine HIV testing. Providers had described in the first focus group that they typically recommend HIV testing to their patients only if risk factors were present, i.e. intravenous drug use or men having sex with men. A consequence of these concerns seemed to be that providers preferred, if an outreach program were conducted, that content be posted on the PHR website, rather than transmitted via email. Patients and providers approved of a "tickler" email message to patients that would indicate there is new content on the PHR, with a hyperlink to the PHR website.

\section{Perceived provider burden}

A prominent provider concern was that electronic outreach for disease screening would lead to unmanageable workload. They anticipated the outreach would result in a substantial increase in patient phone calls, time spent explaining and clarifying the outreach program, and additional appointments.

"If the VA is going to send out a newsletter [about disease screening],...especially if you're sending it electronically,...you're going to get this flood of phone calls the day it goes out, and probably the next week. And, if you're not prepared for that, you've got to have your telephone staff prepared. You have to have your primary care nursing staff prepared, your primary care provider staff. Because these things have this, like, volcano effect." (Provider FG2)

One provider suggested that the messages should contain preemptive language to discourage patients from immediately calling or visiting their provider:

"If you maybe send out [an electronic] newsletter [to patients that says] '.. your provider will be asking you for A, B, C, D, E, F, G at your annual - highlighted, underlined, in bold, different color - visit', so [the patients realize] you don't need a PSA every time you come to the walk-in." (Provider FG1)

These providers did not reject the electronic outreach initiative, but have suggested that to be successful, it would be wise to make advance preparations with staff and to include education of patients that indicates this is not urgent and can be handled at annual - or other regularly scheduled visits. Other providers concurred, but also reflected a feeling that PCPs are being 
shouldered with increasing demands and performance measures, often without increases in resources:

"How can I do this? I want to be doing X, Y, and Z, and you're adding another element that I'm responsible for." (Provider FG1)

Patients, interestingly, did not indicate they would rush to contact their providers or make appointments to see their doctors as a result of electronic messages. In fact some patients believed that if the electronic communication had links to more information it might actually save doctors time:

"If you need more information...instead of having an hour conversation with the doctor and having the doctor teach you, you could actually go to a place on [the patient website for more information]." (Patient FG2)

\section{Discussion}

As health care systems adopt new information technologies it is appropriate to consider their use for public health purposes, such as disease screening. This study takes a first, exploratory step in evaluating the acceptability of outreach via an electronic PHR system by soliciting patient and provider perceptions through focus groups. We found that perceptions were, on the whole, positive. Patients and providers acknowledged educational, informational, and motivational benefits of electronic messages. Providers especially, and patients to a much smaller degree, expressed privacy concerns about messages that contained HIV content. Those concerns could be mitigated by posting patient content on the PHR website, as opposed to embedding it in personal email messages. A bigger issue for providers, however, was that this kind of outreach could lead to unacceptable increases in workload. They suggested it could be mitigated by increased primary care resources and management of patient flow so that most additional disease screening could occur during annual visits or spread more evenly over time.

Patients indicated that electronic content afforded the ability to view information when and where convenient, at appropriate reading-levels, and with web-links to multiple sources of information. Using individual email addresses, however, carries the potential risk of creating suspicions among patients that they have been contacted based on specific clinical signs of HIV, or based on HIV risk stereotypes, e.g. homosexuality or intravenous drug use. HIV-related stigma also seemed to underlie provider worries that patients would unwittingly expose themselves to stigma if they sent their doctors emails about HIV testing. Accordingly, patients and providers favored an outreach approach that delivered content impersonally, i.e. posted on the healthcare system PHR website.

Our findings support the IMB model in that both patients and providers indicated that the electronic messages were perceived as providing important information, and that they would lead to patient action in terms of inquiries about, or actual increases in, testing. The findings also highlighted to us that the health belief model (HBM) [31] could be an important addition to the IMB model in helping to understand patient and provider responses to electronic messages about disease screening. This makes sense in that the health belief model often guides health-related social marketing campaigns [32-35] that rely on perceived susceptibility to disease to motivate people to take action. Patients with high perceived susceptibility may seek information, screening, and care on their own. Others patients, however, may have consciously or unconsciously suppressed the knowledge that their family history or risky health behaviors could make them vulnerable to certain health conditions. For such patients the electronic messages serve as external cues ("cues to action" in the terminology of HBM) motivating them to take action and get tested. While the current draft messages (Figure 2) incorporate concepts of information and motivation from the IMB model, future versions could have links to skill-building material - another important IMB component. For example the HIV message could link to material about how to have a conversation with a partner about using condoms, while the diabetes message could link to simple instructions for increasing daily physical activity.

It is noteworthy that the participating patients were middle aged and older adults, most of whom were not highly experienced computer and Internet users. Nevertheless nearly all recognized advantages that such technologies provide in distributing beneficial health information, a finding supported by Pew Research Center findings that older adults are increasing their presence online [36,37].

Provider concerns that electronic communications with patients may create unmanageable workloads have been documented previously [38]. Evidence suggests, however, that patient use of PHRs, secure messaging, and similar electronic communication tools do not overwhelm providers $[39,40]$. There is even evidence that electronic communication reduces in-person and telephone communication [6]. We found support for this, e. g. a patient stating that accessing information from a website could replace "an hour conversation with the doctor". The above notwithstanding, we do not dismiss provider concerns about increased workloads. Primary 
care providers face health system demands for better quality of care at lower costs, with resultant increased stress and loss of autonomy [41,42]. On the other hand solutions exist to even out demands on providers, for example by staggering electronic outreach messages based on patient birth dates or social security numbers.

The success of HIV screening campaigns may rest partly on patient perceptions that, in the event of a positive HIV test, they can gain access to compassionate providers and effective treatments, i.e. there is good linkage to care [43-45]. When HIV screening outreach is conducted by a health facility or system that has strong HIV care programs, it is likely the outreach will be more successful. In this regard, the VA would seem to be especially well suited to employ the kind of electronic outreach described in our study because it is a large, comprehensive health care system with specialized HIV clinics to care for veterans with HIV/AIDS. Currently approximately 23,000 veterans with $\mathrm{HIV}$ are in treatment in the VA [46].

This study was conducted 6 months before the VA formally adopted CDC guidelines which recommend routine HIV testing for all adults in care, regardless of risk factors [47]. This policy change eliminated written patient informed consent for HIV testing, in favor of verbal consent. Thus our findings represent patient and provider perceptions prior to implementation of the new HIV testing policy in the VA. Adherence to the CDC guidelines is far from universal even after the policy change in the VA and in other settings [48], suggesting the importance of continued outreach to patients to encourage HIV testing. In addition even in settings where the guidelines are closely adhered too, there will be patients who come for care infrequently and thus would benefit from this kind of outreach; the outreach messages might prompt them to make a visit or a phone call to discuss testing with their provider. In any case it will be important to evaluate whether patient and provider perceptions of HIV testing messages have changed in the VA and to extend the analysis to non VA sites.

As PHR systems continue to expand their capabilities, it is easy to imagine moving from occasional broad electronic outreach programs to more routine patient reminders that patients see when they open up their PHR. In the VA, for example, the PHR has recently implemented reminders for preventive care and procedures, such as diabetes care (foot and retinal exams), cancer screening, and immunizations [49]. It would not be difficult, technically, to add HIV screening to that list.

\section{Limitations}

Our study was limited to 2 patient focus groups and 2 provider focus groups conducted in one region of the $U$.
S. Thus our findings may not be generalizable to other regions and other healthcare systems. Only 2 female patients participated ( 1 in each group), also limiting generalizability. Our participants were middle-aged and older, and thus probably reacted differently to some issues than would participants in their 20s and 30s who have grown up with computers. Also participant responses might have differed had they been reacting to a "live" electronic outreach program rather than a proposed one. Our use of draft text, however, which participants reviewed in the focus groups, is likely to have created a sense of concreteness and immediacy.

\section{Conclusions}

The growth in online information systems connecting healthcare organizations with their patients provides an excellent opportunity to conduct low cost and potentially high impact electronic outreach and social marketing. Our findings suggest that patients and providers endorse the use of PHRs for disease screening outreach, even for a stigmatized health condition such as HIV. For providers it is important that prior to initiating wide-scale electronic outreach forethought be given to management of patient expectations and flow. Before large scale implementation of such a program, validation from other geographic regions and with other age groups would be beneficial. If executed properly, electronic outreach campaigns through PHR systems may lead to increased screening, increased detection, and improved health.

\section{Additional material}

Additional file 1: Focus group guides used for patients and providers. A text file with the two patient focus group guides and the two provider focus group guides.

\section{Acknowledgements and Funding}

This study was supported by the Department of Veterans Affairs, Veterans Health Administration, Health Services Research and Developoment Service Quality Enhancement Research Initiative (RRP 08-251). Additionally DK

McInnes was supported by a VA Career Development Award (CDA 09-016). The views expressed in this article are those of the authors and do not necessarily represent the views of the Department of Veterans Affairs. We wish to thank Linda McCoy, Joanne Anctil, and Jane Burgess for their help with this study. We also thank the patients and primary care providers who took part in the study.

\section{Author details}

${ }^{1}$ Center for Health Quality, Outcomes \& Economic Research, ENRM VA Medical Center, Bedford, MA, USA. ${ }^{2}$ Boston University School of Public Health, Boston, MA, USA. ${ }^{3}$ VA Palo Alto Health Care System, Palo Alto, CA, USA. ${ }^{4}$ Division of General Medical Disciplines, Stanford School of Medicine, Stanford, CA, USA. ${ }^{5}$ A Public Health Strategic Health Care Group, Washington, DC, USA. ${ }^{6}$ VA Veterans and Consumers Health Informatics Office, Washington, DC, USA. 'Boston University School of Medicine, Boston, MA, USA. 


\section{Authors' contributions}

$\mathrm{KM}$ and $\mathrm{AG}$ wrote the initial study protocol. KM and JS conducted the focus groups. JS, BB, and KM anaylzed the data. All authors contributed to interpretation of data. KM wrote the manuscript, which was commented on by all the other authors. All authors have read and approved the final version of the manuscript.

\section{Competing interests}

The authors declare that they have no competing interests.

Received: 24 June 2011 Accepted: 15 August 2011

Published: 15 August 2011

\section{References}

1. Palella FJ Jr, Deloria-Knoll M, Chmiel JS, Moorman AC, Wood KC, Greenberg AE, Holmberg SD: Survival benefit of initiating antiretroviral therapy in HIV-infected persons in different CD4+ cell strata. Ann Intern Med 2003, 138(8):620-626.

2. Centers for Disease Control and Prevention: Late HIV testing - 34 states, 1996-2005. MMWR Morb Mortal Wkly Rep 2009, 58(24):661-665.

3. Kitahata MM, Gange SJ, Abraham AG, Merriman B, Saag MS, Justice AC, Hogg RS, Deeks SG, Eron JJ, Brooks JT, et al: Effect of early versus deferred antiretroviral therapy for HIV on survival. N Engl J Med 2009, 360(18):1815-1826.

4. Anonymous: Screening for HIV: recommendation statement. Ann Intern Med 2005, 143(1):32-37.

5. Glynn M, Rhodes P: Estimated HIV prevalence in the United States at the end of 2003. Abstract: T1-B1101. Proceedings of the National HIV Prevention Conference 2005

6. Chen C, Garrido T, Chock D, Okawa G, Liang L: The Kaiser Permanente Electronic Health Record: transforming and streamlining modalities of care. Health Aff (Millwood) 2009, 28(2):323-333.

7. Silvestre AL, Sue VM, Allen JY: If you build it, will they come? The Kaiser Permanente model of online health care. Health Aff (Millwood) 2009, 28(2):334-344.

8. Kaelber D, Pan EC: The value of personal health record (PHR) systems. AMIA Annu Symp Proc 2008, 343-347.

9. Amico KR, Barta W, Konkle-Parker DJ, Fisher JD, Cornman DH, Shuper PA, Fisher WA: The Information-Motivation-Behavioral Skills Model of ART Adherence in a Deep South HIV+ Clinic Sample. AIDS Behav 2009, 13(1):66-75.

10. Kalichman SC, Cain D, Fuhrel A, Eaton L, Di Fonzo K, Ertl T: Assessing medication adherence self-efficacy among low-literacy patients: development of a pictographic visual analogue scale. Health Educ Res 2005, 20(1):24-35.

11. Hibbard JH, Stockard J, Mahoney ER, Tusler M: Development of the Patient Activation Measure (PAM): conceptualizing and measuring activation in patients and consumers. Health Serv Res 2004, 39(4 Pt 1):1005-1026.

12. Enwald HP, Huotari ML: Preventing the obesity epidemic by second generation tailored health communication: an interdisciplinary review. $J$ Med Internet Res 12(2):e24.

13. Block G, Sternfeld B, Block CH, Block TJ, Norris J, Hopkins D, Quesenberry CP $\mathrm{Jr}$, Husson G, Clancy HA: Development of Alive! (A Lifestyle Intervention Via Email), and its effect on health-related quality of life, presenteeism, and other behavioral outcomes: randomized controlled trial. $J$ Med Internet Res 2008, 10(4)::43.

14. Olshefsky AM, Zive MM, Scolari R, Zuniga M: Promoting HIV risk awareness and testing in Latinos living on the U.S.-Mexico border: the Tu No Me Conoces social marketing campaign. AIDS Educ Prev 2007, 19(5):422-435.

15. Healthfinder.gov. [http://www.healthfinder.gov/]

16. Department of Veterans Affairs: Caring for Veterans with HIV Disease: Characteristics of Veterans in VA Care, Fiscal Year 2002. Public Health Strategic Health Care Group, Center for Quality Management in Public Health; 2003.

17. Anaya HD, Hoang T, Golden JF, Goetz MB, Gifford A, Bowman C, Osborn T, Owens DK, Sanders GD, Asch SM: Improving HIV screening and receipt of results by nurse-initiated streamlined counseling and rapid testing. J Gen Intern Med 2008, 23(6):800-807.

18. Goetz MB, Hoang T, Bowman C, Knapp H, Rossman B, Smith R, Anaya H, Osborn T, Gifford AL, Asch SM: A system-wide intervention to improve
HIV testing in the Veterans Health Administration. J Gen Intern Med 2008, 23(8):1200-1207.

19. Knapp H, Anaya HD, Feld JE: Expanding HIV rapid testing via point-ofcare paraprofessionals. Int J STD AIDS 2008, 19(9):629-632.

20. Owens DK, Sundaram V, Lazzeroni LC, Douglass LR, Tempio P, Holodniy M, Sanders GD, Shadle VM, McWhorter VC, Agoncillo T, et al: HIV testing of at risk patients in a large integrated health care system. J Gen Intern Med 2007, 22(3):315-320.

21. Perlin J: Need for Routine Human Immunodeficiency Virus (HIV) Risk Assessment and Testing (IL 10-2005-017).Edited by: Affairs V. Washington, DC; 2005:

22. Dookeran NM, Burgess JF Jr, Bowman CC, Goetz MB, Asch SM, Gifford AL: HIV screening among substance-abusing veterans in care. I Subst Abuse Treat 2009, 37(3):286-291.

23. Nazi KM, Woods SS: MyHealtheVet PHR: A Description of Users and Patient Portal Use. AMIA Annu Symp Proc 2008, 1182.

24. Fisher JD, Fisher WA: Changing AIDS-risk behavior. Psychol Bull 1992, 111(3):455-474.

25. Kalichman S, Stein JA, Malow R, Averhart C, Devieux J, Jennings T, Prado G, Feaster DJ: Predicting protected sexual behaviour using the InformationMotivation-Behaviour skills model among adolescent substance abusers in court-ordered treatment. Psychol Health Med 2002, 7(3):327-338.

26. Kitzinger J: Qualitative research. Introducing focus groups. BMJ 1995, 311(7000):299-302

27. Kidd PS, Parshall MB: Getting the focus and the group: enhancing analytical rigor in focus group research. Qual Health Res 2000 10(3):293-308.

28. Kitzinger J: The methodology of focus groups: the importance of interaction between research participants. Sociology of Health and IIIness 1994, 16(1):103-121.

29. Charmaz K: Constructing Grounded Theory. Thousand Oaks, CA: Sage; 2006.

30. Zavestoski S, Brown P, McCormick S, Mayer B, D'Ottavi M, Lucove JC: Patient activism and the struggle for diagnosis: Gulf War illnesses and other medically unexplained physical symptoms in the US. Soc Sci Med 2004, 58(1):161-175.

31. Janz NK, Champion VL, Strecher VJ: The Health Belief Model. In Health Behavior and Health Education.. 3 edition. Edited by: Glanz K, Rimer BK. Lewis FM. San Francisco: John Wiley 2002:

32. Bauer UE, Johnson TM, Hopkins RS, Brooks RG: Changes in youth cigarette use and intentions following implementation of a tobacco control program: findings from the Florida Youth Tobacco Survey, 1998-2000. JAMA 2000, 284(6):723-728.

33. Ling JC, Franklin BA, Lindsteadt JF, Gearon SA: Social marketing: its place in public health. Annu Rev Public Health 1992, 13:341-362.

34. Futterman DC, Peralta L, Rudy BJ, Wolfson S, Guttmacher S, Rogers AS: The ACCESS (Adolescents Connected to Care, Evaluation, and Special Services) project: social marketing to promote HIV testing to adolescents, methods and first year results from a six city campaign. $J$ Adolesc Health 2001, 29(3 Suppl):19-29.

35. Noar SM, Palmgreen P, Chabot M, Dobransky N, Zimmerman RS: A 10-year systematic review of HIV/AIDS mass communication campaigns: Have we made progress? J Health Commun 2009, 14(1):15-42.

36. Lenhart A, Purcell K, Smith A, Zickuhr K: Social Media and Young Adults. Pew Internet \& Americal Life Project Washington, DC: Pew Research Center; 2010.

37. Madden M: Older Adults and Social Media. Pew Internet \& Americal Life Project Washington, DC: Pew Research Center; 2010.

38. Halamka JD, Mandl KD, Tang PC: Early experiences with personal health records. J Am Med Inform Assoc 2008, 15(1):1-7.

39. Sands DZ, Halamka JD: PatientSite: patient centered communication services, and access to information. In Consumer Informatics: Applications and Strategies in Cyber Health Care. Edited by: Nelson R, Ball MJ. New York: Springer-Verlag; 2004:

40. Hess R, Bryce CL, Paone S, Fischer G, McTique KM, Olshansky E, Zickmund S, Fitzgerald $K$, Siminerio $L$ : Exploring challenges and potentials of personal health records in diabetes self-management: implementation and initial assessment. Telemed J E Health 2007, 13(5):509-517.

41. Linzer M, Manwell LB, Williams ES, Bobula JA, Brown RL, Varkey AB, Man B, McMurray JE, Maguire A, Horner-lbler B, et al: Working conditions in 
primary care: physician reactions and care quality. Ann Intern Med 2009, 151(1):28-36, W26-29.

42. Lakhan SE, Laird C: Addressing the primary care physician shortage in an evolving medical workforce. Int Arch Med 2009, 2(1):14.

43. Craw JA, Gardner LI, Marks G, Rapp RC, Bosshart J, Duffus WA, Rossman A, Coughlin SL, Gruber D, Safford LA, et al: Brief strengths-based case management promotes entry into HIV medical care: results of the antiretroviral treatment access study-ll. Journal of acquired immune deficiency syndromes (1999) 2008, 47(5):597-606.

44. Gardner LI, Metsch LR, Anderson-Mahoney P, Loughlin AM, del Rio C, Strathdee S, Sansom SL, Siegal HA, Greenberg AE, Holmberg SD: Efficacy of a brief case management intervention to link recently diagnosed HIVinfected persons to care. AIDS (London, England) 2005, 19(4):423-431.

45. Manirankunda L, Loos J, Alou TA, Colebunders R, Nostlinger C: "It's better not to know": perceived barriers to HIV voluntary counseling and testing among sub-Saharan African migrants in Belgium. AIDS Educ Prev 2009, 21(6):582-593.

46. Department of Veterans Affairs Public Health Strategic Health Care Group: The State of Care for Veterans with HIV/AIDS. Washington, DC; 2009.

47. Department of Veterans Affairs: Elimination of Requirement for Prior Signature Consent and Pre and Post-Test Counseling for HIV Testing. Federal Register 38 CFR Part 17 Washington DC; 2009.

48. Jain CL, Wyatt CM, Burke R, Sepkowitz K, Begier EM: Knowledge of the Centers for Disease Control and Prevention's 2006 routine HIV testing recommendations among New York City internal medicine residents. AIDS patient care and STDs 2009, 23(3):167-176.

49. My HealtheVet. [https://www.myhealth.va.gov/mhv-portal-web/anonymous. portal?_nfpb=true\&_nfto=false\&_pageLabel=aboutMHVHome].

doi:10.1186/1756-0500-4-295

Cite this article as: McInnes et al: Use of electronic personal health record systems to encourage HIV screening: an exploratory study of patient and provider perspectives. BMC Research Notes 2011 4:295.

\section{Submit your next manuscript to BioMed Central} and take full advantage of:

- Convenient online submission

- Thorough peer review

- No space constraints or color figure charges

- Immediate publication on acceptance

- Inclusion in PubMed, CAS, Scopus and Google Scholar

- Research which is freely available for redistribution

Submit your manuscript at www.biomedcentral.com/submit
Biomed Central 